This is the accepted manuscript of the article, which has been published in Psychiatry research

2019, vol 272, 387-391

https://doi.org/10.1016/i.psychres.2018.12.090

\title{
Tanning dependence and seasonal affective disorder are frequent among sunbathers but are not associated
}

Anna Toledo ${ }^{\mathrm{a}}$ Emmi Yli-Uotila ${ }^{\mathrm{a}}$, Hannu Kautiainen ${ }^{\mathrm{b}}$, Sami Pirkola ${ }^{\mathrm{c}}$, Timo Partonen ${ }^{\mathrm{d}}$, Erna Snellman ${ }^{\mathrm{a}, \mathrm{e}}$

aniversity of Tampere, Faculty of Medicine and Life-Sciences. Faculty of Medicine and Life Sciences, Department of Dermatology and Venereology. Lääkärinkatu 1, 33520 Pirkanmaa, Finland.

${ }^{b}$ Unit of Primary Health Care, Helsinki University Central Hospital, Department of General Practice, University of Helsinki, and Unit of Primary Health Care, Kuopio University Hospital, Helsinki and Kuopio. Tukholmankatu 8 B, 00290 Helsinki and Puijonlaaksontie 2, 70210 Kuopio, Finland.

'University of Tampere, Faculty of Social Sciences, and National Institute for Health and Welfare (THL). Lääkärinkatu 1, 33520 Pirkanmaa and Mannerheimintie 166, Helsinki, Finland.

${ }^{\mathrm{d}}$ National Institute for Health and Welfare (THL). Mannerheimintie 166, Helsinki, Finland.

'Tampere University Hospital, and University of Tampere, Faculty of Medicine and Life Sciences. Lääkärinkatu 1, 33520 Pirkanmaa and Teiskontie 35, 33521 Tampere, Finland

Disclosure of interest: The authors report no conflict of interest. 


\section{Highlights}

- Of respondents $50 \%$ sunbathed frequently.

- One third of the sunbathers appeared either tanning dependent/abuser.

- Tanning dependent/abusers sunbathed significantly more frequently.

- $42.2 \%$ of sunbathers showed subsyndromal/definite seasonal affective disorder.

- Sunbathing related tanning dependence/abuse and SAD symptoms were not associated. 


\begin{abstract}
Ultraviolet radiation (UVR) is a known risk factor for skin cancers. Those who are tanning dependent seek out UVR exposure. Many tanners have expressed symptoms of seasonal affective disorder (SAD), but conclusive evidence of a connection with tanning dependence is lacking. We evaluated the frequency of tanning dependence or abuse and symptoms of SAD among Finnish sunbathers and analysed whether phenomena are associated which could indicate a common biological mechanism. Sunbathing related tanning dependence/abuse among Finnish sunbathers were assessed using the Structured Interview for Tanning Abuse and Dependence measure (SITAD), and symptoms of SAD were assessed with the Seasonal Pattern Assessment Questionnaire (SPAQ). Of 229 sunbathers, 8\% $(n=18)$ were classified as tanning-dependent, and 26\% ( $n=59)$ were classified as tanning abusers. Additionally, 16\% $(n=37)$ met the criteria for SAD, and 26\% ( $n=60)$ met the criteria for subsyndromal seasonal affective disorder (S-SAD), but there was no significant association between tanning dependence or abuse and SAD or S-SAD. Sunbathing dependence or abuse and SAD/S-SAD were frequent among sunbathers, and they may promote sun-seeking risk behaviour. However, within this sample, tanning dependence and SAD/S-SAD were not associated.
\end{abstract}

Keywords: SITAD; SPAQ; addiction; sunlight; skin cancer 


\section{Introduction}

Ultraviolet radiation (UVR) exposure has been causally linked to the development of nonmelanoma skin cancers and malignant melanomas (Gandini et al., 2011; Tierney et al., 2015). Many sunbathers and indoor tanners are aware of the harmful effects of UVR but continue to seek a tan (Feldman et al., 2004; Nolan et al., 2009; O’Leary et al., 2014). Some of the difficulty in ceasing tanning has been attributed to UVR addiction (Ashrafioun and Bonar, 2014; Feldman et al., 2004; Harrington et al., 2011; Nolan et al., 2009), which has been unofficially regarded as a subtype of behavioural addiction.

A theoretical framework for the assessment of tanning-related substance-related disorder proposes that exposure to sunlight accelerates the synthesis of endogenous endorphins in the skin, which may reinforce tanning behaviour and, at least in some circumstances, explain the addictive nature of sunbathing (Warthan et al., 2005). In an earlier study blocking opioid receptors with systemic naltrexone reduced the UVR preference and induced withdrawal-like symptoms in some frequent tanners (Kaur et al., 2006). In mice, frequent low-dose UV-B exposures induced epidermal $\beta$ endorphin synthesis, increased plasma $\beta$-endorphin levels and raised the pain threshold (Fell et al., 2014). Moreover, naloxone was capable of eliciting withdrawal signs in mice after chronic UV-B exposure, and this was related to formation of $\beta$-endorphin in the skin (Fell et al., 2014; Skobowiat and Slominski, 2015). Artificial narrow-band UV-B exposures also increased $\beta$-endorphin expression in human skin in vivo (Jussila et al., 2016), and earlier human studies detected increased levels of endorphins after UVR, although subsequent studies in men have not confirmed this finding (Belon, 1985; Gambichler et al., 2002; Levins et al., 1983; Warthan et al., 2005; Wintzen et al., 2001). 
The modified Cut down, Annoyed, Guilty, Eye-opener (m-CAGE) measure detected problematic indoor tanning behaviour in $11 \%$ to $33 \%$ of respondents, mostly representing university/college students or frequent indoor tanners (Ashrafioun and Bonar, 2014; Harrington et al., 2011; Heckman et al., 2008; Mosher and Danoff-Burg, 2010; Poorsattar and Hornung, 2007; Warthan et al., 2005). Using the criteria of the American Psychiatric Association's Diagnostic and Statistical Manual of Mental Disorders, Fourth Edition, Text Revision (DSM-IV-TR), for substance dependence but being modified for tanning dependence, tanning dependence was found in 23-53\% of participants (American Psychiatric Association, 2000; Ashrafioun and Bonar, 2014; Harrington et al., 2011; Heckman et al., 2008; Mosher and Danoff-Burg, 2010; Warthan et al., 2005). Using the self-administered Structured Interview for Tanning Abuse and Dependence (SITAD), 5.4\% of the participants met the criteria for tanning dependence and $10.8 \%$ for tanning abuse. The respondents were randomly selected college students in East Tennessee State University (First et al., 1995; Hillhouse et al., 2012). SITAD was based on the criteria for substance dependence but modified to detect tanning dependence and abuse behaviour, whereas the modified m-CAGE and DSM-IV-TR were intended to identify substance dependence (Warthan et al., 2005).

Seasonal affective disorder (SAD) is a condition of regularly occurring depression during autumn or winter, with remission in the following spring or summer (Rosenthal et al., 1984). Subsyndromal seasonal affective disorder (S-SAD) shows similar but milder symptoms (Partonen and Lönnqvist, 1998). SAD/S-SAD is common in northern latitudes, where the amount of sunlight is scarce in wintertime (Magnusson, 2000). Excessive indoor tanning and SAD have shown a positive relationship (Heckman et al., 2016; Hillhouse et al., 2010, 2005; Petit et al., 2014), which may suggest that individuals may indoor tan as a form of self-treatment on account of its moodenhancing properties (Heckman et al., 2016; Petit et al., 2014). SAD was reported earlier to be 
three times more frequent among subjects with tanning dependence than among subjects with no tanning dependence (Cartmel et al., 2017). However, among female university students SAD was not significantly associated with tanning dependence (Heckman et al., 2014). In a study with women indoor tanners the presence of SAD was associated with more problematic tanning and tanning to improve mood and relax (Culnan et al., 2015). In another study frequent indoor tanners had higher than expected rates of SAD, body dysmorphic disorder and elevated stress (Blashill et al., 2016). To the best of our knowledge there are no studies on the association between tanning dependence and seasonal symptoms in northern latitudes, where SAD/S-SAD is a common finding. Our study is also the first study to use SITAD in an outdoor sunbathing context to assess sunbathing related tanning dependence/abuse.

In winter time people tend to travel to sunny resorts to get tanned, to improve their mood and to energize. Our aim was to assess the presence of sunbathing related tanning dependence among Finnish sunbathers using the SITAD measure with sunbathing related wording (Hillhouse et al., 2012), and to explore whether tanning dependence/abuse shows a positive relationship with SAD/S-SAD. We hypothesized that tanning dependence is frequent among sunbathers and some beach and parkgoers may sunbathe for the mood-enhancing effects in summertime.

\section{Methods}

The research plan was approved by the Ethics Committee of Pirkanmaa Hospital District (\#R15001). The sunbathers were informed about the study and agreed to participate by responding anonymously either using an internet link or posting their answers in a prepaid envelope.

\subsection{Participants and Recruitment}


Finnish-speaking adults encountered on beaches or in parks in July and August 2015 were eligible for inclusion in the study. We approached people on beaches and in parks in two Finnish cities, Tampere and Pori $\left(61^{\circ} \mathrm{N}\right)$, and asked them to participate in the survey. The responses to the questionnaires were voluntary, no rewards were offered. No distinction was made between genders or between families, couples, groups or single people in terms of recruitment. A total of 393 questionnaires, 199 paper questionnaires and 194 internet links to questionnaires, were supplied.

\subsection{Measures}

The demographic and background data gathered included Fitzpatrick's skin phototyping (Fitzpatrick, 1988). The most sensitive skin phototype, type I, always burns and never tans; type II often burns and tans poorly; type III sometimes burns and tans easily; type IV never burns and tans rapidly; types V and VI refer to brown and black skin (Fitzpatrick, 1988). Since the skin phototype I does not tan, we proposed the number of respondents presenting the phototype I to remain low among sunbathers. The questions also delineated whether sunbathing was intended for the specific purpose of tanning the skin, whether the individual sunbathed seldom/occasionally or frequently (defined whenever possible in purpose to tan), and the frequency of sunscreen use (never, occasionally, frequently, always). Smoking (yes/no and, if yes the number of cigarettes smoked per day and how soon the first cigarette is smoked after awakening) and alcohol consumption (never, once a month, 2-4 times a month, 4 times a week or more often and, if alcohol is consumed, the number of portions per day and how often six portions or more are consumed a day). These habits were asked elicited as addictive behaviours may coincide.

We used the SITAD measure to differentiate tanning-dependent individuals and abusers from non-dependent individuals. SITAD is based on opioid use items adapted from the Structured 
Clinical Interview for Diagnostic and Statistical Manual of Mental Disorders, Fourth Edition, Axis I Disorders (SCID) (First et al., 1995). Depending on choice of wording, it can be used to detect either indoor or outdoor tanning dependence or both (Hillhouse et al., 2012). In the present study wording was adjusted to consider in specific sunbathing related tanning dependence. The SITAD questions differentiate tanning dependent, tanning abusers and non-dependent respondents (Hillhouse et al., 2012). For tanning dependence, the respondent needed to fulfil at least three of the following criteria: 1) loss of control over tanning; 2) unsuccessful efforts to cut down or control tanning; 3) a great deal of time spent on tanning, preparations for it, or recovery from it; 4) social problems due to tanning; 5) physical or psychological problems due to tanning; 6) tolerance of the effects of tanning; or 7) withdrawal symptoms attributable to tanning (Hillhouse et al., 2012). A respondent was defined as a tanning abuser if the criteria for dependence were not met but at least one of the following was present: 1) recurrent tanning accompanied by failure to fulfil role expectations at work or school, 2) physically hazardous recurrent tanning, or 3) continued tanning in the presence of recurrent social or interpersonal problems. There were altogether 13 main items with one to four sub-questions after removing one item, as "legal problems" was deemed inappropriate for the sunbathing context (Hillhouse et al., 2012). The measure was translated following the WHO guidelines (World Health Organization, 1948. http://www.who.int/substance_abuse/research_tools/translation/en/\#). Completion of the SITAD measure takes about five minutes.

The presence of seasonal variations in mood and behaviour was evaluated using the Seasonal Pattern Assessment Questionnaire (SPAQ), which yields a numerical Global Seasonality Score (GSS) (Magnusson, 1996). The sunbathers were classified by means of the SPAQ into those fulfilling the criteria for SAD and S-SAD and for normal seasonal variations in mood and 
behaviour (normal seasonality). Briefly, the seasons may give rise to changes in six items tied to well-being and behaviour (i.e., mood, appetite, weight, sleep duration, energy level, and social activity), which may vary from no change (0) to mild (1), moderate (2), definite (3) or severe (4). The sum of these item scores is the GSS, ranging 0-24 (Kasper et al., 1989; Magnusson, 1996; Rosenthal et al., 1987). Respondents reported whether these seasonal variations were a problem and, if they were, its severity (mild to disabling). Accordingly, a respondent was defined as having SAD when the GSS ranged from 11 to 24 points and the severity of seasonal problems was graded as at least moderate (Kasper et al., 1989). S-SAD was defined as a GSS score of 11 to 24 with no or only mild seasonal problems, or as a GSS score of 9 to 10 with at least mild problems. Normal seasonality was defined as a GSS score of 0 to 8 , or 9 to 10 but with no seasonal problems.

\subsection{Statistical methods}

Mean values and their standard deviations (SD) were calculated for continuous variables and frequencies were calculated for categorical variables. Statistical significances for the hypothesis of linearity across categories of tanning dependence were evaluated by using the CochranArmitage test for trend and analysis of variance with an appropriate contrast. The relationship of seasonality and tanning dependence was tested with logistic regression adjusted for confounding factors. Simulations were used to calculate post hoc power for the relationship of seasonality and tanning dependence by using the actual data from this study. All analyses were performed using Stata Statistical Software, Release 15.1 (StataCorp LP, College Station, TX, USA).

\section{Results}

The response rate was 59\% ( $n=229)$, and 70\% ( $n=161)$ of responses arrived via the internet. There was a female predominance $84 \%$ (193/229) among responses. According to the tanning 
dependence measure SITAD targeting sunbathing related tanning dependence, 34\% ( $n=77)$ of sunbathers were screened as positive, with $8 \%(n=18)$ fulfilling the criteria for tanning dependent and 26\% ( $n=59)$ for tanning abusers (Table 1.).

Altogether $42 \%$ ( $n=97$ ) of the sunbathers were classified to display either SAD $(16 \%, n=37)$ or SSAD $(26 \%, n=60)$. A total of $28 \%(n=63)$ of sunbathers reported seasonal variations in mood and behaviour to be a definite problem, with 6\% $(n=14)$ having severe or disabling problems. SAD/SSAD and tanning dependence or abuse showed no association $(p=0.54)$ and the share of normal seasonality, S-SAD or SAD was equal independent of the tanning dependence classification. The history of ever having used a solarium and having sunbathed frequently to tan was both significantly associated with tanning dependence, whereas the proportion of photosensitive respondents decreased significantly as degree of tanning dependence increased, as seen in Table 1.

Altogether 50\% $(n=115)$ of respondents sunbathed frequently whenever possible (Table 1$)$, but there was a highly significant linear difference between non-dependent (37\%), tanning abusers (75\%), and tanning dependent respondents (83\%) $(p<0.001)$. Of all respondents $94 \%(n=215)$ had sometimes sunbathed with the specific intention of tanning their skin, but those who were tanningdependent or abusers did so significantly $(p=0.036)$ more frequently. Table 1 shows that $67 \%$ of tanning-dependent and of 58\% of abusers had tanned their skin indoors, compared to $40 \%$ of nondependent beach and parkgoers, showing a linear significant difference $(p=0.004)$. Only 1.3\% $(n=3)$ were frequent indoor tanners, and 20,1\% $(n=46)$ had used solarium for a specific occasion, 
and $17,5 \%(n=40)$ were random users. The frequency of using sunscreen, smoking or drinking habits were not significantly associated with tanning dependence/abuse (Table 1).

No statistical relationship between seasonality and sunbathing related tanning dependence was detected ( $p$ for linearity 0.35 , post hoc power $74 \%$ ). To evaluate if essential co-variates had an impact on the relationship between seasonality and tanning dependence we conducted an analysis 1) with the original crude data, 2) with the age and gender-adjusted data, and 3) with the co-variates smoking, drunkenness and sun sensitive skin (phototypes I-II) data in addition to age and gender (Table 2.). The models showed that co-variates had no impact on the outcome, nor were any significant associations between seasonality and tanning dependence detected.

\section{Discussion}

In our study we assessed sunbathing related tanning dependence among beach and parkgoers using SITAD, showing that $34 \%$ of the Finnish beach and parkgoers were tanning dependent or abusers (Hillhouse et al., 2012). This highlights that tanning addiction must be considered an important factor which may lead to excessive sunbathing and thus increase the risk of getting contracting skin cancer. SAD/S-SAD symptoms were detected in $42 \%$ of beach and parkgoers. Respective figures were published earlier in a large Finnish population study reporting S-SAD in 38.9\% and SAD in 2.6\% (Grimaldi et al., 2009).

Warthan et al. assessed motivations for beachgoing among 145 sunbathers on Galveston Island, Texas. Using the mCAGE measure and the mDSM-IV-TR measure, $26 \%$ of sunbathers met the mCAGE and 53\% the mDSM-IV-TR diagnostic criteria for tanning addiction (Warthan et al., 2005). Due to the use of different measures, these results are not directly comparable with ours, 
although they undeniably indicate the magnitude of the tanning dependence issue. The mCAGE has been criticized for the use of detecting tanning dependence. The criticism has arisen due to the different wording between studies, for screening subjects who had not tanned themselves indoors recently as problematic tanners and for giving too high percentages for tanning related problems (Schneider et al., 2015).

Hillhouse et al., who developed the SITAD measure, performed a pilot study showing that $16 \%$ of 296 college students met the criteria for indoor tanning dependence/abuse (Hillhouse et al., 2012). Interestingly, in our sample targeting sunbathing related tanning dependence, the frequency of tanning dependent or abusers was double. This gap could be related to the beach and park context, as well as the different cultures and northern geographic locations in our study with minimal sunlight for several months a year, which may be conducive to sun-seeking behaviour.

In the present study up to $16 \%$ scored high, thereby fulfilling the criteria for SAD and exceeding the figure of 2.6\% detected by Grimaldi et al. in the national population survey (Grimaldi et al., 2009). Earlier, Hillhouse et al. reported that $81 \%$ of frequent indoor tanners exhibited either SAD or S-SAD, supporting the idea that tanning beds are used for their mood-enhancing effects (Hillhouse et al., 2005). To conclude, both sunbathing and indoor tanning seem to attract people presenting with more severe seasonality and may serve as an attempt to cure symptoms, as suggested earlier (Heckman et al., 2016; Petit et al., 2014). Other explanations are possible, since Grimaldi et al. reported $85 \%$ of a national cohort to follow some seasonal pattern in their mood and behaviour (Grimaldi et al., 2009). The discrepancy in seasonality figures between Hillhouse's study and ours could also be due to the season in which the studies were conducted and to other potential differences involving seasonal availability, proximity to home, engaging alone or with friends (Hillhouse et al., 2005). 
Contradicting our hypothesis, in the present study SAD/S-SAD was not associated with sunbathing related tanning dependence. Another recent study found that meeting the criteria for SAD was associated with tanning dependence (Cartmel et al., 2017). Of specific types of psychiatric disorders, tanning dependence was associated with "being more likely to meet criteria for SAD" (Heckman et al., 2014). Nevertheless, consistent with our findings, Heckman et al., using the Positive Affect and Negative Affect Scale (PANAS), reported a lack of association between mood states, including both negative (upset, scared, irritable, nervous, jittery, afraid) and positive (feeling interested) mood states and tanning addiction and speculated that this finding might indicate that tanning-dependent individuals have developed tolerance of the mood-enhancing effects of tanning but continue to tan as a hallmark of dependence (Heckman et al., 2016; Watson et al., 1988).

In the northern regions, when daylight is scarce in wintertime, SAD symptoms are a frequent finding (Magnusson, 2000). Bright light therapy through the eyes may effectively cure SAD (Partonen and Lönnqvist, 1998), but it is not known if UVR exposures through the skin have a definite impact on mood. Whether exposures of the skin using visible light or UVR induce neuroendocrine changes needs further study (Fell et al., 2014; Felton et al., 2017; Jussila et al., 2016; Skobowiat and Slominski, 2015; Skobowiat et al., 2011). A recent study using brain imaging techniques with single photon emission computerized tomography (SPECT) showed that addicted tanners express stronger neural rewarding responses to UVR than do non-addicted tanners, supporting the existence of a cutaneous-neural connection (Aubert et al., 2016). UV induced endocannabinoids have also been linked with sunbathing and mood (Felton et al., 2017). Some studies propose that genetic involvement may play a role in tanning addiction (Cartmel et al., 2017; 
Cartmel et al., 2014; Khouja et al., 2018). Further research is therefore still needed as the mechanisms remain far from clear.

Excessive tanning of the skin is a frequent concern of health care authorities due to the everincreasing prevalence of skin cancers, including melanomas (Gandini et al., 2011; Tierney et al., 2015). Our results show that one-third of beach and parkgoers met the criteria for sunbathing related tanning dependence/abuse, justifying the serious concern about the skin cancer risk in tanning-dependent individuals. New interventions are therefore urgently needed to halt addictions like harmful tanning behaviour. Hillhouse et al. presented an appearance-focused intervention booklet that might be useful, independent of SAD status, in preventing tanning dependence (Hillhouse et al., 2010).

The research group who published SITAD has now moved on to using another shorter instrument, the Behavioral Addiction Indoor Tanning Screener, BAITS (Diehl et al., 2018; Stapleton et al., 2016). BAITS was not available when we conducted our study; it is also designed for indoor tanning users and there are no published studies using BAITS in the sunbathing context.

There were some limitations in our study. First, the summer when data was collected was very rainy and chilly, allowing sunbathing on only very few days, which may have influenced the sample content and its size. The survey was implemented only in summertime, which may have impacted on the presence of SAD/S-SAD. The results are context-dependent and confined to Finnish beach and parkgoers.

\section{Conclusions}

Sunbathing related tanning dependence/abuse and symptomatic seasonality (SAD/S-SAD) were both frequent among Finnish sunbathers but not associated with each other. Further targeted 
experimental and longitudinal clinical studies are necessary to elucidate and understand these phenomena to improve efficacy in the prevention of skin cancers.

\section{Acknowledgements}

We cordially thank Professor Joel Hillhouse for permission to use the Structured Interview for Tanning Abuse and Dependence measure in our study.

Funding sources: This work was supported by the Competitive State Research Financing, grant \#9P065 and \#9T061, within the relevant Expert Responsibility Area of Tampere University Hospital. 


\section{References}

American Psychiatric Association, Task Force on DSM IV, 2000. Diagnosis and Statistical Manual of Mental Disorders: DSM-IV-TR, Washington, DC: APA Task Force on DSM-IV.

Ashrafioun L., Bonar E.E., 2014. Tanning addiction and psychopathology: further evaluation of anxiety disorders and substance abuse. J Am Acad Dermatol. 70, 473-480.

Aubert P.M., Seibyl J.P., Price J.L., Harris T.S., Filbey F.M., Jacobe H., et al. , 2016. Dopamine efflux in response to ultraviolet radiation in addicted sunbed users. Psychiatry Research: Neuroimaging. 251, 7-14.

Belon E., 1985. UVA exposure and pituitary secretion. Variations of human lipotropin concentrations ( $\beta \mathrm{LPH})$ after UVA exposure. Photochemistry and Photobiology. 42, 327-329.

Blashill A.J., Oleski J.L., Hayes R., Scully J., Antognini T., Olendzki E., et al., 2016. The Association Between Psychiatric Disorders and Frequent Indoor Tanning. JAMA Dermatol. 152, 577-579.

Cartmel B., Bale A.E., Mayne S.T., Gelernter J.E., DeWan A.T., Spain P., et al., 2017. Predictors of tanning dependence in white non-Hispanic females and males. J Eur Acad Dermatol Venereol. 31, 1223-1228.

Cartmel B., Dewan A., Ferrucci L.M., Gelernter J., Stapleton J., Leffell D.J., et al., 2014. Novel gene identified in an exome-wide association study of tanning dependence. Experimental Dermatology. 23, 757-771.

Culnan E., Kloss J.D., Darlow S., Heckman C.J., 2015. Associations between seasonal sleep change and indoor tanning. Psychol Rep. 116, 523-533. 
Diehl K., Görig T., Breitbart E.W., Greinert R., Hillhouse J.J., Stapleton J.L., et al., 2018. First evaluation of the Behavioral Addiction Indoor Tanning Screener (BAITS) in a nationwide representative sample. Br J Dermatol. 178, 176-182.

Feldman S.R., Liguori A., Kucenic M., Rapp S.R., Fleischer A.B. Jr, Lang W., et al., 2004. Ultraviolet exposure is a reinforcing stimulus in frequent indoor tanners. J Am Acad Dermatol. $51,45-51$.

Fell G.L., Robinson K.C., Mao J., Woolf C.J., Fisher D.E., 2014. Skin $\beta$-endorphin mediates addiction to UV light. Cell. 157, 1527-1534.

Felton S.J., Kendall A.C., Almaedani A.F.M., Urquhart P., Webb A.R., Kift R., et al., 2017. Serum endocannabinoids and $\mathrm{N}$-acyl ethanolamines and the influence of simulated solar UVR exposure in humans in vivo. Photochemical Photobiological Sciences. 16, 564-574.

First M., Spitzer R., Gibbon M., Williams J.B., 1995. Structured Clinical Interview for DSM-IV axis I disorders (SCID), Biometrics Research Department, New York State Psychiatric Institute, New York, NY.

Fitzpatrick T.B., 1988. The validity and practicality of sun-reactive skin types I through VI. Arch Dermatol. 124, 869-871.

Gambichler T., Bader A., Vojvodic M., Avermaete A., Schenk M., Altmeyer P., et al., 2002. Plasma levels of opioid peptides after sunbed exposures. Br J Dermatol. 147, 1207-1211.

Gandini S., Autier P., Boniol M., 2011. Reviews on sun exposure and artificial light and melanoma. Prog Biophys Mol Biol. 107, 362-366. 
Grimaldi S., Partonen T., Haukka J., Aromaa A., Lönnqvist J., 2009. Seasonal vegetative and affective symptoms in the Finnish general population: testing the dual vulnerability and latitude effect hypotheses. Nord J Psychiatry. 63, 397-404.

Harrington C.R., Beswick T.C., Leitenberger J., Minhajuddin A., Jacobe H.T., Adinoff B., 2011. Addictive-like behaviors to ultraviolet light among frequent indoor tanners. Clin Exp Dermatol. 36, 33-38.

Heckman C., Darlow S., Cohen-Filipic J., Kloss J., 2016. Mood changes after indoor tanning among college women: associations with psychiatric/addictive symptoms. Health Psychol Res. 4, 5453.

Heckman C.J., Cohen-Filipic J., Darlow S., Kloss J.D., Manne S.L., Munshi T., 2014. Psychiatric and addictive symptoms of young adult female indoor tanners. J Am Health Promot. 28, 168-174.

Heckman C.J., Egleston B.L., Wilson D.B., Ingersoll K.S., 2008. A preliminary investigation of the predictors of tanning dependence. Am J Health Behav. 32, 451-464.

Hillhouse J., Stapleton J., Turrisi R., 2005. Association of frequent indoor UV tanning with seasonal affective disorder. Arch Dermatol. 141, 1465.

Hillhouse J., Turrisi R., Stapleton J., Robinson J., 2010. Effect of seasonal affective disorder and pathological tanning motives on efficacy of an appearance-focused intervention to prevent skin cancer. Arch Dermatol. 146, 485-491.

Hillhouse J.J., Baker M.K., Turrisi R., Shields A., Stapleton J., Jain S., et al., 2012. Evaluating a measure of tanning abuse and dependence. Arch Dermatol. 148, 815-819. 
Jussila A., Huotari-Orava R., Ylianttila L., Partonen T., Snellman E., 2016. Narrow-band ultraviolet B radiation induces the expression of $\beta$-endorphin in human skin in vivo. J Photochem Photobiol B. 155, 104-108.

Kasper S., Rogers S.L., Yancey A., Schulz P.M., Skwerer R.G., Rosenthal N.E., 1989.

Phototherapy in individuals with and without subsyndromal seasonal affective disorder. Arch Gen Psychiatry. 46, 837-844.

Kaur M., Liquori A., Lang W., Rapp S.R., Fleischer A.B. Jr, Feldman S.R., 2006. Induction of withdrawal-like symptoms in a small randomized, controlled trial of opioid blockade in frequent tanners. J Am Acad Dermatol. 54, 709-711.

Khouja J., Lewis S.J., Bonilla C., 2018. Influence of maternal and own genotype at tanning dependence-related SNPs on sun exposure in childhood. BMC Med Genet. 19, 62.

Levins P.C., Carr D.B., Fisher J.E., Momtaz K., Parrish J.A., 1983. Plasma beta-endorphin and beta-lipoprotein response to ultraviolet radiation. Lancet. 16, 166.

Magnusson A., 2000. An overview of epidemiological studies on seasonal affective disorder. Acta Psychiatr Scand. 101, 176-184.

Magnusson A., 1996. Validation of the seasonal pattern assessment questionnaire (SPAQ). J Affect Disorders. 40, 121-129.

Mosher C.E., Danoff-Burg S., 2010. Addiction to indoor tanning: relations to anxiety, depression, and substance use. Arch Dermatol. 146, 412-417.

Nolan B.V., Taylor S.L., Liguori A., Feldman S.R., 2009. Tanning as an addictive behavior: a literature review. Photodermatol Photoimmunol Photomed. 25, 12-19. 
O’Leary R.E., Diehl J., Levins P.C., 2014. Update on tanning: more risks, fewer benefits. J Am Acad Dermatol. 70, 562-568.

Partonen T., Lönnqvist J., 1998. Seasonal affective disorder. Lancet. 352, 1369-1374.

Petit A., Kaliral L., Chalmin F., Lejoyeux M., 2014. Phenomenology and psychopathology of excessive indoor tanning. Int J Dermatol. 53, 664-672.

Poorsattar S.P., Hornung R.L., 2007. UV light abuse and high-risk tanning behavior among undergraduate college students. J Am Acad Dermatol. 56, 375-379.

Raison C.L., Hale M.W., Williams L.E., Wager T.D., Lowry C.A., 2014. Somatic influences on subjective well-being and affective disorders: the convergence of thermosensory and central serotonergic systems. Front Psychol. 13, 1580.

Rosenthal N., Bradt G., Wehr T., 1984. Seasonal pattern assessment questionnaire. Bethesda, Maryland: National Institute of Mental Health.

Rosenthal N.E., Rotter A., Jacobsen F.M., Skwerer R.G., 1987. No mood-altering effects found after treatment of normal subjects with bright light in the morning. Pshychiatry Res. 22, 1-9.

Schneider S., Schirmbeck F., Bock C., Greinert R., Breitbart E.W., Diehl K., 2015. Casting shadows on the prevalence of tanning dependence: an assessment of mCAGE criteria. Acta Derm Venereol. 95, 162-168.

Skobowiat C., Dowdy J.C., Sayre R.M., Tuckey R.C., Slominski A., 2011. Cutaneous hypothalamic-pituitary-adrenal axis homolog: regulation by ultraviolet radiation. Am J Physiol Endocrinol Metab. 301, E484-E493. 
Skobowiat C., Slominski A.T., 2015. UVB activates hypothalamic-pituitary-adrenal axis in C57BL/6 mice. J Invest Dermatol. 135, 1638-1648.

Stapleton J.L., Hillhouse J.J., Turrisi R., Baker K., Manne S.L., Coups E.J., 2016. The behavioral addiction indoor tanning screener (BAITS): An evaluation of a brief measure of behavioral addictive symptoms. Acta Derm Venereol. 96, 552-553.

Tierney P., de Gruijl F.R., Ibbotson S., Moseley H., 2015. Predicted increased risk of squamous cell carcinoma induction associated with sunbed exposure habits. Br J Dermatol. 173, 201-208.

Warthan M.M., Uchida T., Wagner R.F. Jr., 2005. UV light tanning as a type of substancerelated disorder. Arch Dermatol. 141, 963-966.

Watson D., Clark L.A., Tellegen A., 1988. Development and validation of brief measures of positive and negative affect: the PANAS scales. J Pers Soc Psychol. 5, 1063-1070.

Wintzen M., Ostjin D.M., Polderman M.C., le Cessie S., Burbach J.P., Vermeer B.J., 2001. Total body exposure to ultraviolet radiation does not influence plasma levels of immunoreactive betaendorphin in man. Photodermatol Photoimmunol Photomed. 17, 256-260.

World Health Organization, 1948. WHO Process of translation and adaption of instruments. Retrieved from http://www.who.int/substance_abuse/research_tools/translation/en/\# 
Table 1. Characteristics of sunbathers

\begin{tabular}{|c|c|c|c|c|}
\hline & $\begin{array}{c}\text { Non- } \\
\text { Dependent } \\
n=152\end{array}$ & $\begin{array}{c}\text { Abusers } \\
n=59\end{array}$ & $\begin{array}{c}\text { Dependent } \\
n=18\end{array}$ & $p$-value* \\
\hline Age, mean (SD) & $33(11)$ & $33(9)$ & $37(12)$ & 0.30 \\
\hline Females, $n(\%)$ & $124(82)$ & $53(90)$ & $16(89)$ & 0.16 \\
\hline $\begin{array}{c}\text { Skin phototype, } n(\%) \\
\text { I } \\
\text { II } \\
\text { III } \\
\text { IV }\end{array}$ & $\begin{array}{c}1(1) \\
40(26) \\
67(44) \\
44(29)\end{array}$ & $\begin{array}{c}2(3) \\
7(12) \\
33(56) \\
17(29)\end{array}$ & $\begin{array}{c}0(0) \\
2(11) \\
6(33) \\
10(56)\end{array}$ & 0.034 \\
\hline GSS mean (SD) & $9.5(4.7)$ & $10.8(5.0)$ & $10.5(4.2)$ & 0.13 \\
\hline $\begin{array}{c}\text { Seasonality, } n(\%) \\
\text { Normal } \\
\text { S-SAD } \\
\text { SAD } \\
\end{array}$ & $\begin{array}{l}91(60) \\
40(26) \\
21(14)\end{array}$ & $\begin{array}{l}28(47) \\
18(31) \\
13(22)\end{array}$ & $\begin{array}{l}13(72) \\
2(11) \\
3(17)\end{array}$ & 0.54 \\
\hline Ever used solarium, $n(\%)$ & $61(40)$ & $34(58)$ & $12(67)$ & 0.004 \\
\hline Ever sunbathed to tan, $n(\%)$ & $139(91)$ & $58(98)$ & $18(100)$ & 0.036 \\
\hline Sunbathes frequently to tan, $n(\%)$ & $56(37)$ & $44(75)$ & $15(83)$ & $<0.001$ \\
\hline $\begin{array}{l}\text { Sunscreen use, } n(\%) \\
\text { Never } \\
\text { Occasionally } \\
\text { Frequently }\end{array}$ & $\begin{array}{l}21(14) \\
54(36) \\
77(51)\end{array}$ & $\begin{array}{l}6(10) \\
28(47) \\
25(42)\end{array}$ & $\begin{array}{l}1(6) \\
11(61) \\
6(33)\end{array}$ & 0.52 \\
\hline Smoking, $n(\%)$ & $38(25)$ & $13(22)$ & $6(33)$ & 0.74 \\
\hline $\begin{array}{l}\text { Excessive use of alcohol, often, } n \\
(\%)\end{array}$ & $23(15)$ & $10(17)$ & $2(11)$ & 0.88 \\
\hline
\end{tabular}

Abbreviations: Global Seasonality Score (GSS), Subsyndromal Seasonal Affective Disorder (S-

$\mathrm{SAD})$, Seasonal Affective Disorder (SAD), ${ }^{*} p$ for linearity. 
Table 2. Relationship between seasonality and tanning dependence (dependent/abusers vs. others).

\begin{tabular}{|c|l|l|l|}
\hline & $\begin{array}{l}\text { Model 1 } \\
\text { OR (95\% CI) }\end{array}$ & $\begin{array}{l}\text { Model 2 } \\
\text { OR (95\% CI) }\end{array}$ & $\begin{array}{l}\text { Model 3 } \\
\text { OR (95\% CI) }\end{array}$ \\
\hline $\begin{array}{c}\text { Seasonality } \\
\text { Normal }\end{array}$ & 1.00 (Reference) & 1.00 (Reference) & 1.00 (Reference) \\
S-SAD & $0.32(0.07$ to 1.45$)$ & $0.31(0.07$ to 1.41$)$ & 0.34 (0.07 to 1.58) \\
SAD & $0.81(0.22$ to 3.00$)$ & $0.79(0.21$ to 2.96$)$ & 0.75 (0.20 to 2.85) \\
\hline$p$ for linearity & \multicolumn{1}{|c|}{$p=0.35$} & $p=0.33$ & $p=0.34$ \\
\hline
\end{tabular}

Model 1 was crude. Model 2 was adjusted for age and gender. Model 3 was adjusted for age, gender, smoking, excessive use of alcohol and skin phototype I-II. 